\title{
"PENGARUH PEMBERIAN TUGAS HAFALAN TERHADAP KEMAMPUAN MENGHAFAL SISWA PADA BIDANG STUDI ALQUR'AN HADITS DI MTS HIDAYATUS SHIBYAN DESA KECOMBERAN KECAMATAN TALUN KABUPATEN CIREBON"
}

\author{
Oleh: \\ Akhmad Fahmi, Suteja, H. Suklani \\ Pendidikan Agama Islam (PAI) FITK IAIN SyekhNurjati Cirebon \\ Email: Ahmadfahmi@gmail.com,Suteja@syekhnurjati.ac.id, \\ suklani@syekhnurjati.ac.id
}

\begin{abstract}
ABSTRAK
Penelitian ini memiliki latar belakang dengan masih ditemukannya minat siswa untuk menghafal Al-Qur'an yang belum sesuai harapan, padahal proses pendidikan di MTs Hidayatus Shibyan Desa Kecomberan Kecamatan Talun Kabupaten Cirebon sudah baik. Indikasinya adalah sebagian besar mata pelajaran yang ada di MTs Hidayatus Shibyan memerlukan kemampuan menghafal Al-Qur'an dengan baik, khususnya pada mata pelajaran Al-Qur'an Hadits dan SKL dari AlQur'an Hadits tersebut menitik beratkan pada siswa untuk terampil menghafal AlQur'an terutama Juz 30. Tujuan

Metode

Kesimpulan hasil penelitian ini yaitu, pemberian tugas hafalan pada bidang studi Al-Qur'an Hadits di MTs Hidayatus Shibyan, memperoleh skor 2,51 termasuk dalam kategori rendah, kemampuan menghafal siswa pada bidang studi Al-Qur'an Hadits di MTs Hidayatus Shibyan memperoleh skor 2,85 termasuk dalam kategori rendah dikarenakan jumlah hafalan siswa-siswi MTs Hidayatus Shibyan masih belum tercapai sepenuhnya, dan pengaruh antara pemberian tugas hafalan terhadap kemampuan menghafal siswa pada bidang studi Al-Qur'an Hadits di MTs Hidayatus Shibyan Desa Kecomberan Kecamatan Talun Kabupaten Cirebon memiliki tingkat

Jurnal Pendidikan Agama Islam

198 IAIN Syekh Nurjati Cirebon
\end{abstract}


korelasi yang lemah atau rendah, dengan diperoleh nilai koefisien 0,399 yang menunjukkan pada korelasi yang lemah atau rendah, karena berada pada interval $0,20-0,40$.

\section{A. Pendahuluan}

Al-Qur'an adalah kalam Allah SWT yang diturunkan (diwahyukan) kepada Nabi Muhammad SAW melalui perantaraan malaikat Jibril, yang merupakan mukjizat, yang diriwayatkan secara mutawatir, yang ditulis di mushaf, dan membacanya adalah ibadah), ${ }^{1}$ sedangkan hadits merupakan sumber yang kedua setelah Al-Qur`an. ${ }^{2}$ Fungsi dari hadits sebagai penjelas dari apa-apa yang terdapat di dalam Al-Qur`an, yang mana hadits juga merupakan segala sesuatu yang bersumber dari Rasulullah SAW baik berupa perkataan, perbuatan, atau taqrîr (persetujuan) ataupun sifat darinya dan juga pengakuan beliau terhadap pekerjaan atau perkataan orang lain.

Hadits shahih yang berasal dari Rasulullah SAW sendiri juga tidak diragukan kebenarannya, karena segala perkataan, perbuatan, taqrir (persetujuan ) ataupun sifatnya bukan berasal dari hawa nafsu dirinya, melainkan semuanya berasal dari wahyu Allah. Hal ini telah dijelaskan di dalam Al-Qur`an surat AlNajm [53] ayat 3-4, Allah berfirman:

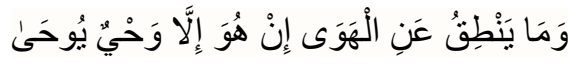

Artinya: “dantidaklah yang diucapkannya (Al-Qur'an) menurutkeinginannya (3). Tidaklah (Al-Qur'an) adalahwahyu yang diwahyukan (kepadanya)" (Q.S. AnNazm [53] : 3-4).

\footnotetext{
${ }^{1}$ Imam Abdullah Muhammad bin Ismail, Shahih Bukhari, terj. dari Shahih Bukhari Juz VI oleh Achmad Sunarto (Semarang: CV. Asy Syifa. Cet 1, 1993), 20.

${ }^{2}$ Muhammad Ahmad dan Mudzakir, UlumulHadis (Bandung: CV. Pustaka Setia. Cet II, 2000), 23.

Jurnal Pendidikan Agama Islam

IAIN Syekh Nurjati Cirebon 
Al-Qur’an dan Hadits seperti sisi mata uang yang tak terpisahkan, karena keduanya berisikan petunjuk bagi manusia menuju jalan yang benar, yang dalam hal ini adalah Islam. ${ }^{3}$

Dapat diketahui bahwa setiap muslim mempunyai tanggung jawab dan kewajiban untuk mengajarkan dan mengamalkan Al-Qur'an sebagai petunjuk dan pedoman hidup seluruh umat manusia yang ada di dunia ini. Apalagi dalam menghadapi tantangan zaman di abad moderen dengan perkembangan dinamika ilmu pengetahuan dan teknologi yang semakin pesat seperti sekarang ini. Masyarakat muslim, khususnya orang tua, ulama, terutama guru di sekolah perlu khawatir dan prihatin terhadap anak-anak sebagai generasi penerus terhadap maju pesatnya iptek yang berdampak pada terjadinya pergeseran budaya sehingga berpengaruh pada pelaksanaan kegiatan pembelajaran Al-Qur'an. ${ }^{4}$

Pada masa sekarang ini, banyak sekali pergeseran nilai dalam kehidupan masyarakat dikarenakan para generasi kita masih banyak yang belum mampu membaca Al-Qur'an dengan baik apalagi menghafal dan memahaminya. Sehingga pihak orang tua harus mengusahakan sedini mungkin untuk mendidik dan membiasakan membaca dan menghafalkan Al-Qur'an.

Di dalam proses pembelajaran di madrasah, khususnya di Madrasah Tsanawiyah Hidayatus Shibyan Desa Kecomberan Kecamatan Talun Kabupaten Cirebon merupakan salah satu lembaga pendidikan setingkat Sekolah Menengah Pertama (SMP) yang menjadikan pendidikan agama Islam sebagai prioritas utama. Dalam hal ini Madrasah Tsanawiyah Hidayatus Shibyan Kecamatan Talun Kabupaten Cirebon mempunyai harapan besar siswa-siswinya mampu menghafal Al-Qur'an dengan baik dan benar. Oleh karena itu, sebagian besar mata pelajaran yang ada di madrasah memerlukan kemampuan menghafal Al-Qur'an dengan

${ }^{3}$ Ahmad Sadali dan Ahmad Rofi'i, Ulumul Qur'an (Bandung: Pustaka Setia, 1997), 11.

${ }^{4}$ Abdul Madjid Khon, Praktikum Qira`at (Jakarta: Amzah. Cet.1, 2008), 25.

Jurnal Pendidikan Agama Islam

200 IAIN Syekh Nurjati Cirebon 
baik, khususnya pada mata pelajaran Al-Qur'an Hadits dan SKL dari Al-Qur'an Hadits tersebut menitik beratkan pada siswanya untuk terampil menghafal AlQuran terutama Juz 30.

Salah satu faktor lain yang mempengaruhi proses pembelajaran adalah adanya pemberian tugas. Tugas merupakan suatu pekerjaan yang menuntut pelaksanaan untuk diselesaikan. Pemberian tugas yang diberikan kepada siswa sebagai upaya agar siswa melakukan kegiatan belajar secara aktif, lebih memahami materi yang telah disampaikan oleh guru. Pemberian tugas tersebut meliputi frekuensi pemberian pekerjaan khusus yang teratur, dalam artian intensitas atau sering tidaknya pemberian tugas yang diberikan oleh guru kepada siswa, kualitas, ketekunan siswa dalam mengerjakan dan tanggung jawab siswa terhadap tugas tersebut.

Dari pendiskripsian di atas, terdapat rumusan masalah dalam penelitian, adakah pengaruh pemberian tugas hafalan terhadap kemampuan menghafal siswa pada Bidang Studi Alqur'an Hadits di MTs hidayatus SHIBYAN DESA Kecomberan Kecamatan talun?

\section{B. LANDASAN TEORI}

\section{Pengertian Pemberian Tugas}

Pemberian tugas dan resitasi adalah metode penyajian bahan dimana guru memberikan tugas tertentu agar siswa melakukan kegiatan belajar. Metode ini diberikan karena dirasakan bahan pelajaran terlalu banyak, sementara waktu sedikit. Artinya, banyaknya bahan yang tersedia dengan waktu kurang seimbang. Agar bahan pelajaran selesai sesuai batas waktu yang ditentukan, maka metode inilah yang biasanya digunakan. ${ }^{5}$

\footnotetext{
${ }^{5}$ Syaiful Bahri dan Aswan Zain, Strategi Belajar Mengajar (Jakarta: Rineka Cipta, 2006), 85.
}

Jurnal Pendidikan Agama Islam 


\section{Hafalan Al-Qur'an danHadits}

Menghafal al-Qur'an terdiri dari dua kata, yaitu kata "menghafal" dan "al-Qur'an". Dalam kamus besar bahasa Indonesia, pengertian menghafal adalah berusaha meresapkan ke dalam pikiran agar selaluingat (Pusat Pembinaan dan Pengembangan Bahasa Depdikbud). Sedangkan al-Qur'an menurut Subhi Salih, al-Qur'an dalah mu'jizat yang diturunkankepadaNabi Muhammad SAW yang tertulis dalam mushaf dan diriwayatkan dengan cara mutawatir dan dipandang sebagai ibadah bagi yang membacanya. ${ }^{6}$ Menurut Ahmad Warson Munawwir", kata "menghafal" dalam bahasa Arab adalah "hifzh". Kata ini berasal dari fi'il (kata kerja) : hafizha-yahfazhu - hifzhan. Jika dikatakan, hafizha asy-syai'a, artinya menjaga (jangan sampai rusak), memelihara dan melindungi. Namun jika dikatakan, hafizha as-sirra, artinya katamahu (menyimpan). Dikatakan, hafizha ad-darsa, artinya istazhharahu (menghafal), menurut Abdul Rauf, ${ }^{8}$ menghafal Al-Qur'an adalah proses mengulang sesuatu, baik dengan membaca atau mendengar karena pekerjaan apapun jika sering diulang pasti menjadi hafal, sedangkan menurut Muhaimin $\mathrm{dkk}^{9}$, menghafal adalah suatu metode yang digunakan untuk mengingat kembali sesuatu yang pernah dibaca secara benar seperti apa adanya. Metode tersebut banyak digunakan dalam usaha untuk menghafal Al-Qur'an dan Al-Hadits.

\section{METODOLOGI DAN PENELITIAN}

\section{Teknik Pengumpulan Data}

\section{a. Angket}

${ }^{6}$ Zaky Mubarok, Akidah Islam (Jogyakarta: UII Press, 2001), 68.

${ }^{7}$ Ahmad Warson Munawwir, Al-Munawwir Kamus Arab Indonesia (Yogyakarta: Yappi-Sinta-Pondok Pesantren Krapyak, 1997), 279.

${ }^{8}$ Abdul Aziz Abdul Rauf, Kiat Sukses Menjadi Hafizh Qur'an Da'iyah (Bandung: Syamil, 2004), 49.

${ }_{9}^{9}$ Muhaimin, dkk. Paradigma Pendidikan Islam Upaya Mengefektifkan Pendidikan Agama Islam (Bandung: Pt. Remaja Rosdakarya, 2002), 30.

Jurnal Pendidikan Agama Islam

202 IAINSyekh Nurjati Cirebon 
Angket atau kuesioner ialah suatu teknik pengumpulan data yang dilakukan dengan cara memberi seperangkat pertanyaan atau pernyataan tertulis kepada responden untuk dijawab. ${ }^{10}$

\section{Wawancara}

Wawancara merupakan proses tanya jawab secara mendalam antara pewawancara dengan informan guna memperoleh informasi yang lebih terperinci sesuai dengan tujuan penelitian. ${ }^{11}$

\section{Observasi}

Observasi adalah suatu cara mengumpulkan data dengan jalan mengadakan pengamatan terhadap kegiatan yang sedang berlangsung.

\section{Dokumentasi}

Dokumentasi merupakan suatu teknik pengumpulan data dengan menghimpun dan menganalisis dokumen-dokumen, baik tertulis, gambar, maupun elektronik. ${ }^{12}$

\section{PEMBAHASAN}

\section{Pemberian Tugas Hafalan Al-Qur'an Hadits}

Tugas merupakan suatu pekerjaan yang harus diselesaikan. Pemberian tugas sebagai suatu metode atau cara mengajar, yaitu pemberian pekerjaan oleh guru kepada siswa untuk mencapai tujuan pengajaran tertentu. Dengan pemberian tugas tersebut siswa belajar mengerjakan tugas. ${ }^{13}$ Dalam

${ }^{10}$ Sugiyono, Metodelogi Penelitian Kuantitatif, Kualitatif Dan R\&D (Bandung: ALFABETA, 2013), 199.

${ }^{11}$ Zainal Arifin, Penelitian Pendidikan Metode dan Paradigma Baru (Bandung: Remaja Rosdakarya, 2012), 170.

12 Nana Syaodih Sukmadinata, Metode Penelitian Pendidikan (Bandung: Pt. Remaja Rosdakarya, 2002), 220-221.

${ }^{13}$ Rauf, Abdul Kiat Sukses 15.

Jurnal Pendidikan Agama Islam

203

IAIN Syekh Nurjati Cirebon 
melaksanakan kegiatan belajar, siswa diharapkan memperoleh suatu hasil perubahan tingkahlaku tertentu sesuai dengan tujuan yang telah ditetapkan

Menghafal adalah suatu metode yang digunakan untuk mengingat kembali sesuatu yang pernah dibaca secara benar seperti apa adanya. Metode tersebut banyak digunakan dalam usaha untuk menghafal Al-Qur'an dan AlHadits. Ada empat langkah yang perlu dilakukan dalam menggunakan metode ini, antara lain:

a. Merefleksi, yakni memperhatikan bahan yang sedang dipelajari, baik dari segi tulisan, tanda bacannya dan syakalnya;

b. Mengulang, yaitu membaca dan atau mengikuti berulang-ulang apa yang diucapkan oleh pengajar;

c. Meresitasi, yaitu mengulang secara individual guna menunjukkan perolehan hasil belajar tentang apa yang telah dipelajari;

d. Retensi, yaitu ingatan yang telah dimiliki mengenai apa yang telah dipelajari yang bersifat permanen.

Yahya Abdul Fattah Az-Zawawi ${ }^{14}$ (2010: 32) menyampaikan bahwa keutamaan menghafal Al-Qur'an adalah:

a. Allah mencintai para penghafal Al-Qur'an

b. Allah menolongparapenghafal Al-Qur'an

c. Al-Qur'an memacusemangatdanmembuatlebihgiatberaktifitas

d. Allah memberkahi para penghafal Al-Qur'an

e. Selalu menemani Al-Qur'an merupakan salah satu sebab mendapat pemahaman yang benar.

f. Doa ahli Al-Qur'an (orang yang hafal Al-Qur'an) tidak tertolak.

g. Orang yang hafal Al-Qur'an adalah orang yang memiliki perkataan baik

${ }^{14}$ Yahya Abdul Fattah Az-Zawawi, Revolusi Menghafal Al Quran (Surakart: insan Kamil, 2010), 32.

Jurnal Pendidikan Agama Islam

IAINSyekh Nurjati Cirebon 
Dengan membaca al-Qur'an berarti kita sedang mengingat Allah dan berkomunikasi dengan-Nya. Dengan selalu mengingat Allah inilah suasana hati akan senantiasa tenang, sebagaimanafirman-Nya dalam al-Qur'an surat $A r-R a^{\prime} d(13: 28)$ :

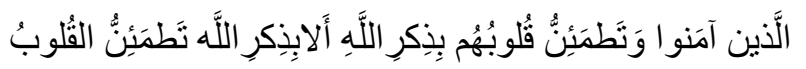

Artinya: "(Yaitu) orang-orang yang beriman dan hati mereka manjadi tenteram dengan mengingat Allah. Ingatlah, hanya dengan mengingati Allahlah hati menjadi tenteram "(Q.S. Ar-Ra'd:28)

Dalam proses belajar, seorang siswa akan memperoleh hasil yang baik jika mampu mengoptimalkan seluruh potensi dalam dirinya. Dengan adanya ketenangan batin/psikis, seorang siswa akan dengan mudah bisa mengoptimalkan seluruh potensi dalam dirinya. ${ }^{15}$

Dari uraian di atas dapat diketahui bahwa aktifitas menghafal al-Qur'an, memiliki keterlibatan terhadap prestasi belajar dalam 2 aspek, yaitu:

a. Proses Menghafal

1) Dalam proses menghafal seorang siswa terbiasa membaca dan mendengar ayat-ayat al-Qur'an, hal ini akan melatih ketajaman indera penglihatan dan pendengarannya terhadap ayat-ayat al-Qur'an tersebut. Selain itu, dengan terbiasa menghafal al-Qur'an, system memori dalam otakak anterlatih untuk mengingat. Hal ini akan memudahkan siswa untuk dapat menghafal pengetahuan lain selain al-Qur'an.

2) Dengan membaca al-Qur'an secara terus-menerus, hati akan menjadi tenang, emosi terkendali, dan keadaan psikologis menjadi baik.

${ }^{15}$ Al-Quran Tajwiddan Terjemah (Bandung: CV Diponegoro. Cet. 5, 2010), 18.

Jurnal Pendidikan Agama Islam

205

IAIN Syekh Nurjati Cirebon 
b. Hafalan al-Qur'an (out put dari aktivitas menghafal)

Al-qur'an secara tidak langsung berpengaruh terhadap pencapaian prestasi belajar siswa pada mata pelajaran karena efek psikologis yang ditimbulkannya, dan secara langsung berimplikasi terhadap mata pelajaran keislaman karena faktor Psikologis dan hasil dari aktivitas menghafal. Dengan adanya hafalan al-Qur'an yang dimiliki siswa tentunya akan dapat membantu dalam mencapai prestasi belajarnya, terutama pada mata pelajaran al-Qur'an Hadits. ${ }^{16}$

Tabel 3.5

KomponenKategoriPenentuan KKM

\begin{tabular}{|c|c|c|c|c|}
\hline No & Komponen & $\begin{array}{l}\text { Kategori } \\
\text { Penilaian }\end{array}$ & $\begin{array}{l}\text { Rentang } \\
\text { Kasar }\end{array}$ & $\begin{array}{c}\text { Rentang } \\
\text { Halus }\end{array}$ \\
\hline 1. & Kompleksitas & $\begin{array}{l}\text { Tinggi } \\
\text { Sedang } \\
\text { Rendah }\end{array}$ & $\begin{array}{l}1 \\
2 \\
3\end{array}$ & $\begin{array}{c}54-60 \\
65-80 \\
81-100\end{array}$ \\
\hline 2. & Dayadukung & $\begin{array}{l}\text { Tinggi } \\
\text { Sedang } \\
\text { Rendah }\end{array}$ & $\begin{array}{l}3 \\
2 \\
1\end{array}$ & $\begin{array}{c}81-100 \\
65-80 \\
54-60\end{array}$ \\
\hline 3. & $\begin{array}{l}\text { Tingkat } \\
\text { kemampuan } \\
\text { Rata-rata siswa } \\
\text { (Intake) }\end{array}$ & $\begin{array}{l}\text { Tinggi } \\
\text { Sedang } \\
\text { Rendah }\end{array}$ & $\begin{array}{l}3 \\
2 \\
1\end{array}$ & $\begin{array}{c}81-100 \\
65-80 \\
54-60\end{array}$ \\
\hline
\end{tabular}

${ }^{16}$ Abdul Fattah Az Zawawi, RevolusiMenghafal Al-Quran, 29.

Jurnal Pendidikan Agama Islam 


\section{E. Kesimpulan}

Berdasarkan hasil penelitian, maka dalam hal ini peneliti dapat mengambil kesimpulan, yaitu:

1. Pemberian tugas hafalan pada bidang studi Al-Qur'an Hadits di Mts Hidayatus Shibyan dilakukan dengan menghafal Al-Qur'an Juz 30. Setiap hari siswa di bombing untuk menghafal dan setoran hafalan kepada guru pembimbingnya yang telah ditetapkan sekolah. Siswa yang belum menyelesaikan hafalan tidak bisa mengikuti ujian semester, karena pemberian tugas hafalan ini menjadi prasyarat untuk mengikuti ujian semester. Berdasarkan perhitungan dari hasil angket pada variabel X tentang pemberian tugas hafalan pada bidang studi Al-Qur'an Hadits di Mts Hidayatus Shibyan pada setiap indikatornya dapat diketahui bahwa skor tertinggi diperoleh pada indikator Cara guru bidang studi Al-Qur'an Hadits memberikan tugas hafalan dengan skor 3,29 (tinggi), begitu juga dengan indicator penilaian pemberian tugas hafalan pada bidang studi Al-Qur'an Hadits dengan skor 3,15 (tinggi), sementara itu indicator Intensitas pemberian tugas hafalan pada bidang studi Al-Qur'an Hadits mendapat skor 2,51 (rendah) artinya Intensitas pemberian tugas hafalan pada bidang studi Al-Qur'an Hadits di MTs Hidayatus Shibyan belum berkembang begitu banyak.

2. Kemampuan menghafal siswa pada bidang studi Al-Qur'an Hadits di MTs Hidayatus Shibyan termasuk dalam kategori baik dikarenakan jumlah hafalan siswa-siswi MTs Hidayatus Shibyan masih belum tercapai sepenuhnya. Hal ini berdasarkan dari hasil analisis data Variabel Y yang dapat disimpulkan bahwa secara umum kemampuan menghafal al-Quran dengan populasi 66 siswa tergolong dalam kategori sangat baik dengan persentase13,6\% atau sebanyak 9 siswa, kategori baik sebesar 48,5\% atau sebanyak 32siswa, kategori sedang sebesar 28,8\% atau 19 siswa dan kategori rendah sebesar 9,1\% atau 6 siswa, sementara untuk kategori sangat rendah tidak ada. Berdasarkan hasil perhitungan

Jurnal Pendidikan Agama Islam

207

IAIN Syekh Nurjati Cirebon 
tersebut kemampuan menghafal siswa pada bidang studi Al-Qur'an Haits berada dalam kategori baik yaitu sebesar 48,5\%.

3. Adapun pengaruh antara pemberian tugas hafalan terhadap kemampuan menghafal siswa pada bidang studi Al-Qur'an Hadits di MTs Hidayatus Shibyan Desa Kecomberan Kecamatan Talun Kabupaten Cirebon memiliki tingkat korelasi yang sangat rendah, diperoleh nilai koefisien Pengaruh Pemberian Tugas Hafalan (Variabel X) Terhadap Kemampuan Menghafal Siswa Pada Bidang Studi Al-Qur'an Hadits (Variabel Y) di MTs Hidayatus Shibyan Kecamatan Talun Kabupaten Cirebon sebesar 0,0597. Hasil tersebut apabila dirubah kedalam skala konservasi, 0,0597 berada pada interval $0,00-0,200$ yang berarti terdapat korelasi yang sangat rendah. Hasil dari koefisien determinasi yang peneliti hitung, menunjukan bahwa Pengaruh Pemberian Tugas Pekerjaan Rumah (Hafalan) Terhadap Kemampuan Menghafal Siswa Pada Bidang Studi Al-Qur'an Hadits di MTs Hidayatus Shibyan Kecamatan Talun Kabupaten Cirebon sebesar 0,356\% sisanya dipengaruhi oleh faktor lain.

\section{DAFTAR PUSTAKA}

Abdullah Muhammad bin Ismail, Imam. (1993). Shahih Bukhari, terj. dari Shahih Bukhari Juz VI oleh Achmad Sunarto. Semarang: CV. Asy Syifa. Cet 1.

Abdul Fattah Az-Zawawi, Yahya, (2010). Revolusi Menghafal Al Quran. Surakart: insan Kamil.

Ahmad dan Mudzakir, Muhammad. (2000). UlumulHadis. Bandung: CV. Pustaka Setia. Cet II.

Arifin, Zainal, (2012). Penelitian Pendidikan Metode dan Paradigma Baru. Bandung: Remaja Rosdakarya.

Aziz Abdul Rauf, Abdul, (2004). Kiat Sukses Menjadi Hafizh Qur'an Da'iyah. Bandung: Syamil.

Jurnal Pendidikan Agama Islam

208 IAIN Syekh Nurjati Cirebon 
Al-Quran Tajwiddan Terjemah (2010). Bandung: CV Diponegoro. Cet. 5.

Bahri, Syaiful, dan Aswan Zain, (2006). Strategi Belajar Mengajar. Jakarta: Rineka Cipta.

Madjid Khon, Abdul, Praktikum Qira`at. Jakarta: Amzah. Cet.1.

Mubarok, Zaky, (2001). Akidah Islam. Jogyakarta: UII Press.

Muhaimin, dkk. (2002). Paradigma Pendidikan Islam Upaya Mengefektifkan Pendidikan Agama Islam. Bandung: Pt. Remaja Rosdakarya.

Sadali, Ahmad dan Ahmad Rofi'i, (1997). Ulumul Qur'an. Bandung: Pustaka Setia. Sugiyono, (2013). Metodelogi Penelitian Kuantitatif, Kualitatif Dan R\&D. Bandung: ALFABETA.

Syaodih Sukmadinata, Nana, (2002). Metode Penelitian Pendidikan. Bandung: Pt. Remaja Rosdakarya.

Warson Munawwir, Ahmad, (1997). Al-Munawwir Kamus Arab Indonesia. Yogyakarta: Yappi-Sinta-Pondok Pesantren Krapyak. 